\title{
Examination and Comparison of Electrically Evoked Compound Action Potentials and Electrically Evoked Auditory Brainstem Response Results of Children with Cochlear Implantation without Inner Ear Anomaly
}

\author{
Seda Bayrak ${ }^{1}$ (D), Başak Mutlu² (D), Günay Kırkım¹ (D), Bülent Şerbetçioğlu ${ }^{3}$ (C) \\ ${ }^{1}$ Department of Audiology, Dokuz Eylül University School of Health Sciences, İzmir, Turkey \\ ${ }^{3}$ Department of Audiology, Medipol University School of Health Sciences, İstanbul, Turkey
}

Original Investigation $>{ }^{2}$ Department of Audiology, İstanbul Medeniyet University School of Health Sciences İstanbul, Turkey

Abstract

ORCID IDs of the authors:

S.B. 0000-0001-8272-5686;

B.M. 0000-0002-9803-9258;

G.K. 0000-0003-4170-5317;

B.S. 0000-0002-5985-097X

Cite this article as: BayrakS, Mutlu B,

Kırkım G, Şerbetçioğlu B. Examination and

Comparison of Electrically Evoked Compound

Action Potentials and Electrically Evoked

Auditory Brainstem Response Results of

Children with Cochlear Implantation without

Inner Ear Anomaly. Turk Arch Otorhinolaryngol

2019; 57(2):81-5.

This study was presented at the VI. National Audiology and Speech Disorders, October, 2012, İstanbul, Turkey

Corresponding Author:

Başak Mutlu; basak.mutlu@medeniyet.edu.tr

Received Date: 29.01.2019

Accepted Date: 09.04.2019

Available Online Date: 27.06.2019

DOl: 10.5152/ta0.2019.4130

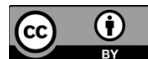

Content of this journal is licensed under a Creative Commons Attribution 4.0 International License.

Available online at www.turkarchotolaryngol.net
Objective: To investigate the relationship between electrically evoked compound action potentials (ECAP) and electrically evoked auditory brainstem responses $(\mathrm{EABR})$ in children with cochlear implants (CI) without inner ear anomalies.

Methods: Sixteen children between the ages of two and six years who were CI users participated in the study. ECAP thresholds were recorded from one electrode in the basal, medial, and apical regions of the cochlear implant. EABRs were recorded from electrodes whose ECAP thresholds were determined. The latency-intensity functions, amplitude and morphological analyzes of the eIII and eV waves at 200 and 180 current unit (CU) excitation levels were performed. The data obtained were analyzed statistically.

Results: ECAP thresholds were found to be $171.5 \pm 11.38,169.69 \pm 20.32$ and $160.81 \pm 20.03 \mathrm{CU}$ at the basal, medial and apical electrodes, respectively. EABR thresholds were also found to be $169.69 \pm 12.17$, $165.62 \pm 16.41$ and $160 \pm 15.49 \mathrm{CU}$ in basal, medial and apical electrodes, respectively. There was a strong pos-

\section{Introduction}

Cochlear implantation is an amplification method used in children and adults with severe and profound sensorineural hearing loss. Effective programming of speech processors, effectively determining the dynamic range, and ensuring that the patient comfortably perceives acoustic stimulants is highly important in cochlear implant (CI) patients (1).

Electrophysiological measurements are performed to assess and adjust the $\mathrm{CI}$ in pediatric patients. These include electrically evoked auditory brainstem response (EABR), electrically evoked stapedi- itive correlation between ECAP and EABR thresholds in apical, medial and basal electrodes $(p<0.05)$. EABR threshold levels were not significantly different between basal, medial and apical region electrodes ( $p>0.05)$, and ECAP threshold values were significantly different between apical and basal region electrodes $(p=0.002)$. When the significance values of $\mathrm{EABR} \mathrm{eV}$ wave latencies were analyzed in terms of electrode region, the difference between basal and apical regions was found to be significant ( $p=0.03$ ).

Conclusion: Consistency was found between ECAP and EABR recordings. However, it was concluded that one could not be preferred over the other because the data quality of the two tests was different. In future studies, ECAP and EABR recordings may be recommended by selecting more electrodes for stimulation.

Keywords: Cochlear implant, electrophysiological studies, electrically evoked compound action potential, electrically evoked auditory brainstem response al reflex threshold (ESRT), electrically compound action potentials (ECAP), middle latency responses (MLR), and cortical responses (CR). ECAP is the most frequently used of these methods, both intraand postoperatively. That it provides limited information about auditory nerve fibrils and creates electrical measurement artefact are its disadvantages. On the other hand, it provides detailed information related to the auditory evoked brainstem activity. However, requires deep sleep or sedation because it is affected by muscle artefact (2-4).

The aim of this study is to identify the relationship between the results of two electrophysiological 
techniques, ECAP and EABR, in pediatric CI users with no inner ear anomaly. The hypothesis of the study was defined as "The relationship between ECAP and EABR results are linear."

\section{Methods}

This study was conducted at the Dokuz Eylül University Hospital, Otorhinolaryngology Department, Hearing-Speech-Balance Unit, included 16 Nucleus CI 24 Contour users aged from two to six years and were radiologically confirmed to have no abnormalities of the inner ear. Consent was obtained from the families of the patients prior to the study. Ethics committee approval was obtained from the Ethics Committee of the Dokuz Eylül University. ECAP recordings were made while patients were awake. Electrical stimuli were created with apical (electrode number 20), medial (electrode number 11) and basal (electrode number 3) electrodes in ECAP and EABR. Recording electrodes were 22, 13 and 5, respectively. ECAP was measured with 25 microsecond/pulse and $50 \mathrm{~Hz}$ stimulus and standard monopolar stimulus (MP1) was used.

Evoked auditory brainstem responses was recorded on a different day than ECAP. Families were asked to keep the child awake the night before and the recording was made during natural sleep using a laptop computer with Medelec Synergy EMG/EP Systems (VIASYS Healthcare, UK) software and equipment. The EABR test protocol was completed in two sessions in some patients. Stimuli were transmitted from the user's processor via a coil by the same $\mathrm{CI}$ firm. Connection between the $\mathrm{CI}$ and the EABR device was established by an external trigger cable compatible with this brand. Three gold disc electrodes were used in recording and each electrode was carefully placed in the same area during every recording. The difference between positive (forehead-hairline border) and negative (mastoid contralateral to the implanted ear) electrodes was recorded in EABR. The earth electrode was placed in the forehead region (Fpz). Electrodes were placed with skin impedance below $2 \mathrm{kOhms}$. EABR recording was carried out at $25 \mathrm{Is} /$ phase intervals and using 20 $\mathrm{Hz}$ monopolar biphasic alternating polarity stimulation. Responses were filtered using $0.1-3000 \mathrm{~Hz}$ analog band-pass filter and amplifier sensitivity was set at $500 \mu \mathrm{V}$. Analysis window was $10 \mathrm{msec}$ and sampling rate was $25 \mathrm{kHz}$. Stimulation was single-channel and simultaneous with the recording. Recording was performed from apical-medial and basal electrodes, respectively. Recording began from the apical region where the most distinct response was evoked $(3,5,6)$. Contralateral placement technique was used to minimize artefact (4, 7-10). Intensity-latency function and morphological analysis of the evoked waves were recorded at 200 and 180 current unit (CU) stimulus levels. Before stimulating at these levels, care was taken not to exceed the comfort level set in the most recent programs of the individuals. Following the recordings at $200 \mathrm{CU}$ and $180 \mathrm{CU}$, stimulus intensity was reduced in increments of 10-units and the last stimulus level at which wave $\mathrm{eV}$ was observed was accepted as the EABR threshold. Stimulation levels 5 units above and below the threshold were also recorded $(11,12)$. At least two tracings were recorded at each stimulation level and the average number in each tracing was set to 1000. ECAP and EABR thresholds of basal, medial and apical electrodes, wave eIII and
$\mathrm{eV}$ latencies at EABR $200 \mathrm{CU}$ and $180 \mathrm{CU}$ and eIII-eV interwave intervals, amplitude levels of eII and $\mathrm{eV}$ waves at this intensity level, and wave $\mathrm{eV}$ morphologies were evaluated.

\section{Statistical Analysis}

Descriptive statistics of nominal, ordinal and numerical data were performed. The significance of the relationship between ECAP and EABR thresholds was analyzed by Spearman correlation test. Wilcoxon signed-rank test was used to analyze the significance of the difference between ECAP and EABR thresholds. Nonparametric Friedman variance analysis was used to determine whether wave eIII and $\mathrm{eV}$ latencies and amplitudes evoked in EABR differed in apical, medial and basal electrodes. A p-value $<0.05$ was accepted as significant. Statistical Package for the Social Sciences version 16.0 (IBM Corp.; Armonk, NY, USA) software was used.

\section{Results}

Of the 16 patients included in the study, 12 were male (75\%) and four were female (25\%). The $\mathrm{CI}$ was in the right ear in 15 patients (94\%) and in the left ear in one patient (6\%). The mean age of the patients was $46.08 \pm 9.13$ months and the mean age of the CIs was $27.03 \pm 8.2$ months. ECAP and EABR responses were evoked by all apical, medial and basal electrodes in all participants. While wave eI could not be recorded due to the masking of the electrical stimulus artefact, waves eII and eIV were observed in some recordings. Waves eIII and eV were evoked in all cases at $200 \mathrm{CU}$. In all electrodes, wave $\mathrm{eV}$ latencies were seen to prolong as stimulus intensity decreased. ECAP and EABR thresholds and wave $\mathrm{eV}$ latencies obtained in EABR thresholds are given in Table 1.

Based on the values given in Table 1, no significant differences were observed between the EABR and the ECAP thresholds in basal, medial and apical regions ( $p>0.05)$. Moreover, the significance of the difference between the ECAP and the EABR thresholds was analyzed in terms of the site of the electrode. EABR thresholds were not found significantly different between basal, medial and apical region electrodes $(p>0.05)$, but ECAP thresholds showed significant differences between apical and basal region electrodes $(\mathrm{p}=0.002)$. When the difference between $\mathrm{EABR}$ wave $\mathrm{eV}$ latencies at the threshold level was analyzed with respect to electrode regions, significant difference was found between basal and apical regions $(\mathrm{p}=0.03)$.

Evoked auditory brainstem response results according to electrode regions are given in Table 2. Wave eIII and eV amplitudes

Table 1. ECAP and EABR thresholds and wave $\mathrm{eV}$ latencies obtained in EABR thresholds

\begin{tabular}{l|c|c|c}
\hline $\begin{array}{l}\text { Mean } \pm \text { Standard } \\
\text { Deviation }\end{array}$ & $\begin{array}{c}\text { ECAP } \\
\text { threshold (CU) }\end{array}$ & $\begin{array}{c}\text { EABR } \\
\text { threshold (CU) }\end{array}$ & $\begin{array}{c}\text { Wave eV latency at } \\
\text { threshold (msec) }\end{array}$ \\
\hline Basal electrode & $171.5 \pm 11.38$ & $169.69 \pm 12.17$ & $4.88 \pm 0.4$ \\
\hline Medial electrode & $169.69 \pm 20.32$ & $165.62 \pm 16.41$ & $4.58 \pm 0.32$ \\
\hline Apical electrode & $160.81 \pm 20.03$ & $160 \pm 15.49$ & $4.53 \pm 0.35$
\end{tabular}

ECAP: electrically compound action potentials; EABR: electrically evoked auditory brainstem response; CU: current unit; msec: millisecond 
Table 2. EABR latency and amplitude levels obtained at 180 and $200 \mathrm{CU}$ by electrode stimulation regions

\begin{tabular}{l|l|c|c|c|c|c|}
\hline $\begin{array}{l}\text { Mean } \pm \\
\text { Standard Deviation }\end{array}$ & $\begin{array}{c}\text { Wave eIII } \\
\text { latency }(\mathrm{msec})\end{array}$ & $\begin{array}{c}\text { Wave eIII } \\
\text { amplitude }(\mu \mathrm{V})\end{array}$ & $\begin{array}{c}\text { Wave eIII } \\
\text { latency }(\mathrm{msec})\end{array}$ & $\begin{array}{c}\text { Wave eV } \\
\text { amplitude }(\mu \mathrm{V})\end{array}$ & $\begin{array}{c}\text { eIII to eV interwave } \\
\text { interval }(\mathrm{msec})\end{array}$ \\
\hline Basal electrode & $200 \mathrm{CU}$ & $2.16 \pm 0.13$ & $0.21 \pm 0.17$ & $4.27 \pm 0.3$ & $0.29 \pm 0.16$ & $2.15 \pm 0.55$ \\
\hline & $180 \mathrm{CU}$ & $2.16 \pm 0.09$ & $0.13 \pm 0.08$ & $4.35 \pm 0.37$ & $0.22 \pm 0.11$ & $2.08 \pm 0.24$ \\
\hline Medial electrode & $200 \mathrm{CU}$ & $2.07 \pm 0.24$ & $0.35 \pm 0.13$ & $4.06 \pm 0.29$ & $0.43 \pm 0.17$ & $2 \pm 0.11$ \\
\hline & $180 \mathrm{CU}$ & $2.09 \pm 0.14$ & $0.18 \pm 0.09$ & $4.22 \pm 0.32$ & $0.23 \pm 0.08$ & $2.05 \pm 0.17$ \\
\hline Apical electrode & $200 \mathrm{CU}$ & $2.04 \pm 0.21$ & $0.38 \pm 0.19$ & $3.93 \pm 0.25$ & $0.4 \pm 0.15$ & $1.9 \pm 0.15$ \\
\hline & $180 \mathrm{CU}$ & $2.17 \pm 0.34$ & $0.24 \pm 0.16$ & $4.1 \pm 0.17$ & $0.29 \pm 0.12$ & $1.93 \pm 0.33$ \\
\hline
\end{tabular}

CU: current unit; msec: millisecond; $\mu \mathrm{V}$ : microvolt; EABR: electrically evoked auditory brainstem response

Table 3. Significance of wave $\mathrm{eV}$ latency differences between intensities of 200 and $180 \mathrm{CU}$ in terms of electrode region ( $\mathrm{p}$ values)

\begin{tabular}{l|c|c}
\hline & $200 \mathrm{CU}$ & $180 \mathrm{CU}$ \\
\hline Basal-apical & 0.002 & 0.13 \\
\hline Basal-medial & 0.004 & 0.86 \\
\hline Apical-medial & 0.049 & 0.37 \\
\hline
\end{tabular}

CU: current unit

and latencies obtained at $180 \mathrm{CU}$ and $200 \mathrm{CU}$, and eIII-eV interwave intervals are shown in this table.

An analysis of wave eV latencies at $200 \mathrm{CU}$ and $180 \mathrm{CU}$ intensity as given in Table 2 showed that wave $\mathrm{eV}$ latencies obtained at $180 \mathrm{CU}$ did not significantly differ $(p>0.05)$, but wave $\mathrm{eV}$ latencies obtained at $200 \mathrm{CU}$ did significantly differ among the electrode regions. These results are given in Table 3.

Differences between EABR wave latencies and amplitudes at $200 \mathrm{CU}$ and $180 \mathrm{CU}$ are given in Table 4. Accordingly, wave eIII and eV latencies and amplitudes were identified to show significant differences at $200 \mathrm{CU}$ and $180 \mathrm{CU}$ stimulation. Only eIII-eV interwave intervals did not show any differences.

Additionally, significant correlation was identified between the EABR and the ECAP thresholds in each of the stimulation regions. Correlation was found uphill and moderate for the basal region, and uphill and high in the medial and apical regions. At the same time, EABR and ECAP levels for the medial and the apical regions were observed to have an uphill and moderate correlation (Table 5).

\section{Discussion}

In all cases included in this study, high-amplitude $\mathrm{eV}$ waves with significant peaks were obtained in the apical region especially at $200 \mathrm{CU}$. Wave eV latencies evoked by apical electrodes were significantly shorter than those evoked by basal electrodes. Also, ECAP thresholds evoked by apical electrodes were found to be lowest and significantly different from those evoked by basal electrodes.

In our study, we also found that ECAP and EABR thresholds showed an uphill, strong and significant correlation among api- cal, medial and basal electrode regions. In a study which they conducted with Nucleus CI users, Brown et al. (13) demonstrated that there were no significant differences between ECAP and EABR thresholds.

Hay-McCutcheon et al. (14) have compared the EABR and EAP (Electrically Evoked Whole-Nerve Action Potential) measurements in 10 postlingual adults with Nucleus CI 24R and Nucleus CI 24M implants, and reported to have found significant difference between the EAP and the EABR thresholds in the Nucleus CI $24 \mathrm{M}$ users, but no significant difference in Nucleus CI 24R users. It is probable that stimulant parameters and/or demographic characteristics of sample groups are different in studies that report significant differences between ECAP and EABR thresholds and the results were affected by these differences.

In a study which Hughes and Stille (6) evaluated the psychophysiological and physiological measurements of electrical field interaction in CI users, they reported that significantly higher ECAP thresholds were evoked by basal electrodes compared to those evoked by apical electrodes. This result is consistent with our results.

Firszt et al. (2) reported high levels in EABR thresholds obtained from apical electrodes. In another study, the same group of authors studied lateral to medial electrode placement in terms of EABR and reported that the electrode regions showed differences by EABR thresholds. They found that the thresholds obtained from medial electrodes were lower and wave amplitudes were higher (15). In our study, EABR thresholds in each of the electrode regions were evaluated and no significant differences were found.

In our study, we found significant difference between the basal and apical electrodes in wave latencies at EABR threshold level. Significantly earlier wave eV latencies were obtained from apical electrodes than basal electrodes. Similar results are also found in the literature $(6,15-17)$. A study investigating the effects of anatomy on EABR reported that wave $\mathrm{eIII}$ and $\mathrm{eV}$ latencies were significantly affected by the stimulated region, and mean latency levels of wave $\mathrm{eV}$ showed an increase of $0.43 \mathrm{msec}$ from the apex to the basal in all electrodes (18). This was explained by the larger diameter of the apical nerve fibers (5). In our study, 
Table 4. Significance of the difference between EABR wave latencies and amplitudes of 200 and $180 \mathrm{CU}(\mathrm{p})$

\begin{tabular}{l|c|c|c|c|c}
\hline & Wave eIII latency & Wave eV latency & eIII to eV interwave interval & Wave eIII amplitude & Wave eV amplitude \\
\hline Basal & 0.005 & 0.010 & 0.87 & 0.003 & 0.008 \\
\hline Medial & 0.007 & 0.002 & 0.08 & 0.003 & 0.002 \\
\hline Apical & 0.001 & 0.001 & 0.31 & 0.001 & 0.001 \\
\hline
\end{tabular}

EABR: electrically evoked auditory brainstem response

Table 5. Analysis of the correlation between EABR and ECAP thresholds

\begin{tabular}{l|c|c|c|c}
\hline \multicolumn{2}{l|}{} & Basal ECAP & Medial ECAP & Apical ECAP \\
\hline Basal EABR & $\mathrm{R}$ & 0.675 & 0.103 & -0.218 \\
\cline { 2 - 5 } & $\mathrm{P}$ & $0.004^{* *}$ & 0.703 & 0.418 \\
\hline Medial EABR & $\mathrm{R}$ & 0.214 & 0.901 & 0.678 \\
\cline { 2 - 5 } & $\mathrm{P}$ & 0.426 & $0.0001^{* *}$ & $0.004^{* *}$ \\
\hline Apical EABR & $\mathrm{R}$ & 0.221 & 0.753 & 0.802 \\
\hline & $\mathrm{P}$ & 0.410 & $0.001^{* *}$ & $0.0001^{* *}$ \\
\hline
\end{tabular}

**: Data showing significance at $\mathrm{p}<0.001$

ECAP: electrically compound action potentials; EABR: electrically evoked auditory brainstem response

wave $\mathrm{eV}$ latency at $200 \mathrm{CU}$ showed a significant difference among all stimulation regions. No significant differences were identified among wave $\mathrm{eV}$ latencies at $180 \mathrm{CU}$ in terms of electrode regions. There are studies that support $(2,15,19,20)$ this result and advocate the opposite $(9,17,21,22)$ in the literature.

In our study, wave eIII latencies were examined at $200 \mathrm{CU}$ and 180 CU intensities. Wave eIII latency at 200 CU was significantly prolonged in the basal electrode. The difference between the apical and the medial electrodes was not significant. No significant differences were identified among wave eIII latencies at $180 \mathrm{CU}$ in terms of electrode regions. This result may suggest that the stimulation level may have affected wave eIII latency since stimulation at higher intensities can both cause latency and stimulate more central areas. This finding has been previously reported in the literature (23). Guirauda et al. (23) reported that wave eIII latency was significantly affected by the stimulated region, and mean latency levels showed an increase of $0.49 \mathrm{msec}$ from the apex to the basal in all electrodes.

No significant differences were found in our study among apical, medial and basal electrodes in the eIII-eV interval at $200 \mathrm{CU}$ and $180 \mathrm{CU}$ intensities. This result was found consistent with the literature. In a study examining the characteristics of hearing loss and the anatomical effects of auditory pathways with EABR, the effect of the stimulated region on wave eIII-eV interval was not found statistically significant (18). In the light of the data obtained in our study and from the literature, we can say that wave eIII latency is prolonged or shortened parallel to the $\mathrm{eV}$ wave latency and this applies to all electrode regions.

In the literature, eII wave latency is reported as $1.30 \mathrm{msec}$, eIII wave latency as $2.10 \mathrm{msec}$, and $\mathrm{eV}$ wave latency as $3.75 \mathrm{msec}$ at a stimulus level close to the maximum behavioral dynamic range.
Similarly, interwave latencies were reported as $0.80 \mathrm{msec}$ for the eII-eIII interval, $1.60 \mathrm{msec}$ for the eIII-eV interval, and 2.40 msec for the eII-eV interval $(2,16,24,25)$. Wave eV amplitude was defined in the range of 1.00 to $1.46 \mu \mathrm{V}$ at high stimulus intensity depending on the recording electrode in the implant electrode array (26). In our study, the results closest to these levels were obtained from apical stimulation at $200 \mathrm{CU}$. Wave eV amplitude at $200 \mathrm{CU}$ did not show a significant difference in the apical and the medial electrodes but decreased significantly in the basal electrode. In our study we also examined wave amplitudes at $180 \mathrm{CU}$ and found no significant differences in wave $\mathrm{V}$ amplitudes with respect to electrode regions. Stimulus intensity, as well as electrode placement alter EABR amplitude.

Each of the EABR response parameters-latency, amplitude and morphology — varies as a function of the electrode position. Wave eV latency of the basal region electrode is longer than that of the apical region electrode $(27,28)$. This result was also found in our study.

In their study they conducted in 2006 with seven adult and seven pediatric Nucleus 24 CI users, Çiprut and Akdaş (29) reported EABR results in which wave $\mathrm{eV}$ amplitudes decreased as stimulus levels decreased, and wave morphology was better in apical channels.

That, in our study, a significant peak was observed in wave $\mathrm{eV}$ in all cases at $200 \mathrm{CU}$ in the apical regions and a decrease was seen towards the basal in the number of cases at the same intensity, is consistent with the studies reporting that the population of live spiral ganglion cells affect the amplitude and morphology variables in EABR waves (18). When the stimulus level decreased to $180 \mathrm{CU}$, the number of cases with significant peaks also decreased. The flattened and ovaliform state which wave eV has assumed from the apical to the basal at $200 \mathrm{CU}$ was also observed at $180 \mathrm{CU}$.

\section{Conclusion}

In EABR, it will be better to select multiple electrodes from each of the basal, medial and apical regions to record responses specific to each stimulation region. In EABR, the most distinct response is evoked at $200 \mathrm{CU}$. EABR recording can be started at this intensity level. At the same time, $200 \mathrm{CU}$ was a sufficient level for demonstrating the characteristics of wave latency and wave morphology. EABR or ECAP recording techniques are not suitable substitutes in CI assessment. While ECAP can be preferred for its clinical practicality, EABR may be more suitable for use in clinical trials because of the more qualitative information it provides. 
Ethics Committee Approval: Ethics committee approval was received for this study from Dokuz Eylül University Non-invasive Researches Ethical Committee (2012/17-24).

Informed Consent: Written informed consent was obtained from the families of the patients who participated in this study.

Peer-review: Externally peer-reviewed.

Author Contributions: Concept - S.B., B.Ş.; Design - S.B., B.Ş.; Supervision - B.Ş., G.K., B.M.; Resource B.Ş., G.K., B.M.; Materials - S.B., B.Ş.; Data Collection and/or Processing - S.B., B.Ş.; Analysis and/or Interpretation - B.Ş., G.K., B.M., S.B.; Literature Search - S.B.; Writing - B.M., S.B.; Critical Reviews - B.Ş., G.K., B.M.

Conflict of Interest: The authors have no conflicts of interest to declare.

Financial Disclosure: The authors declared that this study has received no financial support.

\section{References}

1. Gordon KA, Papsin BC, Harrison RV. Activity-dependent developmental plasticity of the auditory brain stem in children who use cochlear implants. Ear Hear 2003; 24: 485-500. [CrossRef]

2. Firszt JB, Chambers RD, Kraus N, Reeder RM. Neurophysiology of cochlear implant users: Effects of stimulus current level and electrode site on the electrical ABR, MLR, and N1-P2 response. Ear Hear 2002; 23: 502-15. [CrossRef]

3. Cinar BC, Atas A, Sennaroglu G, Sennaroglu L. Evaluation of objective test techniques in cochlear implant users with inner ear malformations. Otol Neurootol 2011; 32: 1065-74. [CrossRef]

4. Şerbetçioğlu B. Periferik ve santral işitsel işlevlerin değerlendirilmesi. Kulak Burun Boğaz Hastalıkları ve Baş Boyun Cerrahisi, Çelik O, editor. 2nd ed. Ankara: Asya Tip Kitabevi, 2007; 19-33.

5. Tavartkiladze GA, Potalova LA, Kruglov AV, Belov A. Effect of stimulation parameters on electrically evoked auditory brainstem responses. Acta Otolaryngol 2000; 120: 214-7. [CrossRef]

6. Hughes ML, Stille LJ. Psychophysical and physiological measures of electrical-field interaction in cochlear implants. J Acoust Soc Am 2009; 125: 247-60. [CrossRef]

7. Møller A R, Janetta PJ. Neural generators of the auditory brainstem response, in Jacobson JT editor. The Auditory Brainstem Response. San Diego: College Hill Press; 1984. p. 13-31.

8. Cords SM, Reuter G, Issing PR, Sommer A, Kuzma J, Lenarz T. A silastic positioner for a modiolus-hugging position of intracochlear electrodes: Electrophysiologic effects. Am J Otol 2000; 21: 212-7. [CrossRef]

9. Abbas PJ, Brown CJ. Electrically evoked brainstem potentials in cochlear implant patients with multi-electrode stimulation. Hear Res 1988; 36: 153-62. [CrossRef]

10. Kileny PR, Zwolan TA, Boerst A, Telian SA. Electrically evoked auditory potentials: Current clinical applications in children with cochlear implants. Am J Otol 1997; 18: S90-2.

11. Thai-Van H, Cozma S, Boutitie F, Disant F, Truy E, Collet L. The pattern of auditory brainstem response wave $\mathrm{V}$ maturation in cochlear-implanted children. Clin Neurophysiol 2007; 118: 676-89. [CrossRef]

12. Runge-Samuelson C, Firszt JB, Gaggl W, Wackym PA. Electrically evoked auditory brainstem responses in adults and children:
Effects of lateral to medial placement of the Nucleus 24 contour electrode array. Otol Neurotol 2009; 30: 464-70. [CrossRef]

13. Brown C J, Hughes ML, Luk B, Abbas PJ, Wolaver A, Gervais $\mathrm{J}$. The relationship between EAP and EABR thresholds and levels used to program the Nucleus 24 speech processor: Data from Adults. Ear Hear 2000; 21: 151-63. [CrossRef]

14. Hay-McCutcheon MJ, Brown CJ, Clay KS, Seyle K. Comparison of electrically evoked whole-nerve action potential and electrically evoked auditory brainstem response thresholds in Nucleus CI24R cochlear implant recipients. J Am Acad Audiol. 2002; 13: 416-27.

15. Abbas PJ, Brown CJ, Shallop JK, Firszt JB, Hughes ML, Hong $\mathrm{SH}$, et al. Summary of results using the Nucleus CI24M implant to record the electrically evoked compound action potential. Ear Hear 1999; 20: 45-59. [CrossRef]

16. Shallop JK, Beiter AL, Goin DW, Mischke RE. Electrically evoked auditory brainstem responses (EABR) and middle latency responses (EMLR) obtained from patients with the Nucleus multichannel cochlear implant. Ear Hear 1990; 11: 5-15. [CrossRef]

17. Miller CA, Abbas PJ, Brown CJ. Electrically evoked auditory brainstem response to stimulation of different sites in the cochlea. Hear Res 1993; 66: 130-72. [CrossRef]

18. Thai-Van H, Gallego S, Veuillet E, Truy E, Collet L. Electrophysiological findings in two bilateral cochlear implant cases: Does the duration of deafness affect electrically evoked auditory brain stem responses? Ann Otol Rhinol Laryngol 2002; 111: 1008-14. [CrossRef]

19. van den Honert C, Stypulkowski PH. Characterization of the electrically evoked auditory brainstem response (ABR) in cats and humans. Hear Res 1986; 21: 109-35. [CrossRef]

20. Stypulkowski PH, van den Honert C, Kvistad SD. Electrophysiologic evaluation of the cochlear implant patient. Otolaryngol Clin North Am. 1986; 19: 249-57.

21. Nagel D. Compound action potential of the cochlear nerve evoked electrically. Electrophysiological study of the acoustic nerve (guinea pig). Arch Otorhinolaryngol 1984; 206: 293-8. [CrossRef]

22. Hermann, B. and Thornton, A. Electrically-evoked auditory brainstem responses in cochlear implant patients. The Second International Cochlear Implant Symposium 1990; pp: 57, Iowa City, IA.

23. Guirauda J, Gallego S, Arnold L, Boyle P, Truy E, Collet L. Effects of auditory pathway anatomy and deafness characteristics? (1): On electrically evoked auditory brainstem responses. Hear Res 2007; 223: 48-60. [CrossRef]

24. Hervé T, Truy E, Durupt I, Collet L. A new stimulation strategy for recording electrical auditory evoked potentials in cochlear implant patients. Electroencephalogr Clin Neurophysiol 1996; 100: 472-8. [CrossRef]

25. Pelizzone M, Kasper A, Montandon P. Electrically evoked responses in cochlear implant patients. Audiology 1989; 28: 230-8. [CrossRef]

26. Hall JW. ABR Parameters, Protocols and Procedures. New Handbook of Auditory Evoked Responses. Boston, Mass: Pearson; 2007. p. 595-7.

27. Abbas P, Brown C. Electrically evoked auditory brainstem response: Growth of response with current levels. Hear Res 1991; 51: 123-37. [CrossRef]

28. Firszt JB, Chambers RD, Kraus N. Neurophysiology of cochlear implant users: Comparison among speech perception, dynamic range, and physiologic measures. Ear Hear 2002; 23: 516-31. [CrossRef]

29. Ciprut A, Akdas F. Electrically evoked auditory brainstem responses in cochlear implant patients. J Int Adv Otol 2007; 3: 6-11. 